\title{
BMJ Open Homeless people's access to primary care physiotherapy services: an exploratory, mixed-method investigation using a follow-up qualitative extension to core quantitative research
}

\author{
Jo Dawes, Stuart Deaton, Nan Greenwood
}

To cite: Dawes J, Deaton S, Greenwood N. Homeless people's access to primary care physiotherapy services: an exploratory, mixed-method investigation using a follow-up qualitative extension to core quantitative research. BMJ Open 2017;7:e012957. doi:10.1136/ bmjopen-2016-012957

- Prepublication history and additional material are available. To view these files please visit the journal online (http://dx.doi. org/bmjopen-2016-012957).

Received 7 June 2016 Revised 22 March 2017 Accepted 4 April 2017

\section{CrossMark}

Faculty of Health, Social Care and Education, a joint faculty between Kingston University and St George's, University of London, London, UK

Correspondence to Jo Dawes; j.dawes@sgul. kingston.ac.uk

\section{ABSTRACT}

Objectives The purpose of this study was to appraise referrals of homeless patients to physiotherapy services and explore perceptions of barriers to access.

Design This exploratory mixed-method study used a follow-up qualitative extension to core quantitative research design. Over 9 months, quantitative data were gathered from the healthcare records of homeless patients referred to physiotherapy by a general practitioner (GP) practice, including the number of referrals and demographic data of all homeless patients referred. Corresponding physiotherapy records of those people referred to physiotherapy were searched for the outcome of their care. Qualitative semi-structured telephone interviews, based on the quantitative findings, were carried out with staff involved with patient care from the referring GP practice and were used to expand insight into the quantitative findings.

Setting Two primary care sites provided data for this study: a GP practice dedicated exclusively to homeless people and the physiotherapy department receiving their referrals.

Participants Quantitative data from the healthcare records of 34 homeless patient referrals to physiotherapy were collected and analysed. In addition, five staff involved in patient care were interviewed.

Results 34 referrals of homeless people were made to physiotherapy in a 9-month period. It was possible to match 25 of these to records from the physiotherapy department. Nine (36\%) patients did not attend their first appointment; seven (28\%) attended an initial appointment, but did not attend a subsequent appointment and were discharged from the service; five (20\%) completed treatment and four patients (16\%) had ongoing treatment. Semi-structured interviews revealed potential barriers preventing homeless people from accessing physiotherapy services, the complex factors being faced by those making referrals and possible ways to improve physiotherapy access.

Conclusions Homeless people with musculoskeletal problems may fail to access physiotherapy treatment, but opportunities exist to make access to physiotherapy easier.
Strengths and limitations of the study

- This study explores homeless people's access to physiotherapy, a topic that previously has received little attention.

- It is a mixed-method study, which uses a follow-up qualitative extension to core quantitative research design and as it is on a small scale, restricted to one GP practice and one physiotherapy department, its findings may not be generalisable.

- The scope of the study did not extend to interviewing homeless people themselves about their experience of accessing physiotherapy, which might have restricted reported perspectives.

- Difficulty matching patient records from two different healthcare record systems resulted in the exclusion of some patient records in the data analysis, potentially distorting conclusions.

\section{INTRODUCTION}

Homeless people are a heterogeneous population, many of whom experience a 'tri-morbidity' of health issues (mental ill health, physical ill health and drug or alcohol misuse combined). ${ }^{1}$ Their mortality is substantially increased, even in countries with good support for those with insecure accommodation. ${ }^{2}$ An ongoing, national study of health and well-being needs of over 3355 homeless people in the UK reports that 2452 $(78 \%)$ have physical health problems, of which $1371(41 \%)$ were joint or muscular problems, ${ }^{3}$ nearly three times as high as that of the general public (14\% of people in England reported musculoskeletal health problems). ${ }^{4}$ In addition, it is recognised that homeless and disadvantaged populations appear to suffer more serious health problems and may not report minor health 
problems as frequently, ${ }^{5}$ therefore musculoskeletal disorders among homeless people may be more serious than among housed people, and homeless people may be under-reporting the less severe problems.

Homeless people can be difficult to reach, and their health problems are often compounded by the barriers they face in accessing healthcare. ${ }^{67}$ Consequently, for this population, even good healthcare may fail to be completely integrated, resulting in diminished effectiveness. ${ }^{1}$ Rapid access to physiotherapy is considered vital in preventing new acute musculoskeletal problems from becoming chronic. ${ }^{8}$ However, there have been no empirical data published on homeless people's access to physiotherapy services.

There are three ways in which National Health Service (NHS)-funded physiotherapy can be accessed: general practitioner (GP) referrals, hospital consultant referrals or self-referrals. Although 98\% of the English population is registered with a GP, a recent study revealed that only $83.3 \%$ of single homeless people with accommodation, $89 \%$ of 'hidden homeless' people (those not included in government statistics, and tending to be out of sight in bed and breakfasts, squats or staying with friends and families) and just $65 \%$ of rough sleepers were registered. ${ }^{6}$ Possible reasons for low GP registration and healthcare referrals among homeless populations may include peripatetic lifestyles, lack of fixed addresses, issues in keeping appointments and restricted access to transport. ${ }^{6}$

It is estimated that homeless people in England attend accident and emergency (A\&E) departments five times more often than the general public. ${ }^{9}$ However, the proportion of these A\&E attendances for non-emergency musculoskeletal problems, which may otherwise be better managed by a physiotherapist in primary care, are unknown. The reasons for their heavier use of A\&E could be a combination of not having to make an appointment and the relative immediacy of assessment, which are likely to be compatible with the unpredictability of homelessness. A 2003 report of physiotherapy services for homeless people in Glasgow, UK showed that uptake improved when the services were provided on a dropin' basis, within homeless centres, and via outreach to hostels ${ }^{10}$ thus suggesting this to be a possible approach to improving access.

London, UK, is a useful city for considering the current situation of homeless people's access to healthcare because of its large homeless population (an estimated 7851 people slept rough during 2014/15 $5^{11}$ and approximately 30000 people were considered and assessed for support from their local authority as a homeless person in 2015). ${ }^{12}$ Although homeless people might find accessing physiotherapy easier by self-referral, it is not consistently offered UK-wide. Engagement with GP services among homeless people is essential, as only 6 out of 32 boroughs in London facilitate self-referral. ${ }^{13}$ Alternatively, a homeless person in London might access physiotherapy via 'Crisis at Christmas' - a volunteer run service providing homeless people with shelter, practical support and health services, including physiotherapy over the Christmas week. Although it only runs 6 days a year, 194 physiotherapy patient sessions were provided in $2015 .{ }^{14}$ Data collected during Crisis at Christmas 2013 showed that the majority of people who used the physiotherapy service had soft tissue injuries, but fewer than half had previously sought help. ${ }^{14}$ Although a short-term service such as this is not comparable to mainstream physiotherapy, nonetheless it is currently the only physiotherapy service tailored specifically to homeless people for which any reportable data exist.

Little is known about the year-round problems of homeless people with musculoskeletal difficulties. In London, some NHS-funded specialist GP practices provide primary care services solely for homeless people. In partnership with one such practice and their receiving NHS physiotherapy department, this exploratory study investigated the accessibility of physiotherapy to homeless people and how their musculoskeletal problems are managed.

\section{Aims of study}

- To appraise all referrals made to physiotherapy from a GP practice caring for homeless people in a 9-month period. This includes numbers of referrals made, demographic information about the people referred and outcome of physiotherapy.

- To summarise the quantitative findings to generate interview questions for the qualitative phase of research.

- To gain further insights regarding the quantitative findings, GP practice staff were interviewed.

\section{METHODS \\ Setting}

Data were gathered from two sites in London, UK. Site A was a GP practice, solely serving a population of approximately 900 homeless and vulnerably housed adults. Site B was an NHS physiotherapy outpatient department, which received all NHS neuromusculoskeletal physiotherapy referrals in that local area, including those from Site A. The Faculty Research Ethics Committee, Faculty of Health, Social Care and Education, Kingston University and St George's, University of London provided ethical approval for the study.

\section{Study design}

This exploratory study employed a follow-up qualitative extension to core quantitative research mixed-method design. ${ }^{15}$ In this study design, the quantitative data described the characteristics of the service referrals, while the qualitative aspect explored the reasons behind the quantitative findings. Two researchers (JD and SD) collected and analysed the data. The design comprised two linked phases. The purposes of the first core quantitative phase were to gather patient data from Sites A and $\mathrm{B}$ and to determine the patterns and treatment of homeless people referred to physiotherapy. The second qualitative phase used semi-structured interviews to 
explore the possible explanatory factors of the quantitative findings from the perspective of the staff from Site A.

\section{Phase 1: Quantitative phase}

Preliminary fieldwork was carried out to understand how patient data could be collected and extracted from patient record systems in each site. Included in the study were all patients from Site A ( $\mathrm{n}=961)$, all of whom were homeless or vulnerably housed. Anonymised data from all patients referred from Site A to Site B over 9 months were collected from the patient records systems at both sites. Excluded from this study were homeless people registered at other GP practices, homeless people who self-referred directly to the physiotherapy department and homeless non-GP referrals to the physiotherapy department.

At Site A, a practice administrator searched the patient record system (Egton Medical Information Systems) for patients referred to physiotherapy during the 9-month study. The following anonymised information was gathered: patient code number, physiotherapy referral date, referrer name, referral reason, age, gender, ethnicity, housing status, support from key worker staff, number of comorbidities (including recorded addiction) and whether a discharge summary had been received from the physiotherapy department.

At Site B, the physiotherapy manager searched the patient record system (CSE Severlec, electronic care record, $\mathrm{RiO}$ ) for all patients referred from Site A. They provided the research team with anonymised summaries of all Site A patient records and anonymised copies of discharge summaries for these patients.

\section{Quantitative data analysis}

As the two sites used different patient record systems, the two anonymised datasets were matched using patients' gender, age at time of referral, referral date and presenting condition. Crosschecking of anonymised discharge summaries was used to maximise match accuracy. JD and SD, who undertook the matching and analysis, were external to the two clinical sites ensuring patient's anonymity was maintained.

The matched data were reported with descriptive statistics (mean, SD, median and ranges) of age, gender and numbers of comorbidities to establish the demographic characteristics of the homeless people referred to physiotherapy. Reasons for referral, attendance patterns, physiotherapy interventions, and outcomes of treatments were also identified and summarised in a quantitative data summary sheet. This formed the outline for qualitative, semi-structured telephone interviews with Site A practice staff.

\section{Phase 2: Qualitative phase}

To understand patterns within the data and staff perspectives, all patients facing GP practice staff $(n=9$, including GPs, nurse practitioners, practice clinical leader, healthcare assistants and reception staff) were invited for a recorded telephone interview. They were provided with a consent form and a participant information sheet.

Participants were e-mailed the quantitative data summary sheet and asked to have this in front of them during their interview. The interviewer used a topic guide, which consisted of open questions relating to the information presented on the quantitative data summary sheet. The interviewer worked through the topic guide, encouraging participants to give as much detail as possible. When necessary, clarification was sought either by the interviewer paraphrasing and repeating back to the interviewee what they had interpreted the interviewee said or by asking the interviewee to explain what they meant. This process of clarification is a form of member checking which can add to the accuracy and credibility of the data gathering process. ${ }^{16}$ With consent, all interviews were digitally recorded and transcribed verbatim. Five staff were interviewed, including two GPs, two nurses and a receptionist.

\section{Qualitative data analysis}

Interview transcripts were analysed using thematic analysis, a six-phase process which involved searching across the data for repeated patterns of meaning (themes). ${ }^{17}$ The phases of analysis used in this study involved: both JD and SD reading and rereading the interview transcripts and becoming thoroughly familiar with the content; both researchers independently generated initial codes and searched for themes within the transcripts; then together JD and SD reviewed and discussed the themes generated, which resulted in defining and naming themes collaboratively. Themes were reviewed by NG, finalised and presented and supported by direct quotes or 'thick descriptions' to provide additional context. ${ }^{18}$

\section{RESULTS}

\section{Quantitative results}

The data presented (table 1) are from patient records for people referred from Site A to Site B during the 9-month study. During that time, 33 patients were referred to physiotherapy (one patient was referred twice, giving 34 patient records in total). Based on the practice having a patient population of 961 patients, this was $3.5 \%$ of the practice population referred in this period. A comparable, although larger, GP practice in the area, with a patient population of 10973 , serving a similar locality, but predominantly housed population, was reported by Site B as making 358 referrals to physiotherapy (average of $4.9 \%$ of the practice population). ${ }^{19}$ Across the two sites, it was possible to match 24 of the $33(72.7 \%)$ patients. As one person was referred twice, there were 25 patient records.

Information about the 24 matched individuals and 25 patient records formed the basis of discussions in the qualitative interviews (table 2). Nine (36\%) patients did not attend their first appointment, which compares to an average of $14 \%$ for the physiotherapy service as a whole. ${ }^{19}$ Seven (28\%) attended an initial appointment, but did 
Table 1 Patient demographic information of referrals from Site A to Site B

\begin{tabular}{|c|c|c|c|}
\hline & & $\begin{array}{l}\text { Patients referred from Site } \\
\text { A to physiotherapy at Site B } \\
(\mathrm{n}=33)\end{array}$ & $\begin{array}{l}\text { Patients matched across both } \\
\text { sites } \\
(n=24)\end{array}$ \\
\hline \multirow[t]{4}{*}{ Age, years } & Mean & 44 & 44 \\
\hline & Median & 48 & 47 \\
\hline & Range & $26-62$ & $27-62$ \\
\hline & SD & 10.4 & 10.9 \\
\hline \multirow[t]{2}{*}{ Gender (\%) } & Male & $25(76)$ & $19(79)$ \\
\hline & Female & $8(24)$ & $5(21)$ \\
\hline \multirow[t]{4}{*}{ Housing status (\%) } & Street homeless & $5(15)$ & $3(13)$ \\
\hline & Housed & $6(18)$ & $5(21)$ \\
\hline & $\begin{array}{l}\text { Hostel/ temporary } \\
\text { accommodation }\end{array}$ & $15(45)$ & $10(42)$ \\
\hline & Squatting/ sofa surfing & $7(21)$ & $6(25)$ \\
\hline \multirow{2}{*}{$\begin{array}{l}\text { Recorded drug or alcohol } \\
\text { problem (\%) }\end{array}$} & Yes & $14(42)$ & $11(46)$ \\
\hline & No & $19(58)$ & $13(54)$ \\
\hline \multirow[t]{2}{*}{ Key worker (\%) } & Yes & 3 (9) & $2(8)$ \\
\hline & No & $30(91)$ & $22(92)$ \\
\hline \multirow[t]{3}{*}{ Reason for referral (\%) } & Back/neck problem & $14(42)$ & $9(38)$ \\
\hline & Upper limb problem & $10(30)$ & $8(33)$ \\
\hline & Lower limb problem & $9(27)$ & $7(28)$ \\
\hline
\end{tabular}

not attend a subsequent appointment and were then discharged from the service. Five $(20 \%)$ completed treatment and four patients (16\%) had treatment ongoing.

A total of 81 physiotherapy sessions were registered among the 24 homeless patients (table 3). Of these appointments, $49(60 \%)$ were attended, 14 (17\%) were cancelled (either by the service or by the patient) and 18 (22\%) were not attended. The mean 'did not attend' (DNA) rate of the physiotherapy service as a whole during the study time frame was $13 \%,{ }^{19}$ showing that the DNA rate among homeless people was higher than the general population. For those attending their initial appointment, the median number of sessions attended was two. The median number of sessions attended by those who completed their treatment and were subsequently discharged from physiotherapy was four (excluding the four patients whose treatment was ongoing). This was similar to the mean number of sessions attended by patients for the physiotherapy service as a whole (4.5). ${ }^{19}$

A greater proportion of those failing to attend their first appointment (six out of nine) had reported drug and/or alcohol dependence problems compared with those who attended. Ten patients had specific interventions documented at Site B. These included: exercise prescription $(\mathrm{n}=8)$; advice (eg, postural advice, health promotion or self management) $(n=6)$ and manual therapy $(n=3)$.

\section{Qualitative results from interviews}

Five digitally recorded interviews with practice staff were carried out over a 1-month period. Supplementary appendix 1 provides summary information about the five staff interviewed. The interviews lasted from between 12 and $20 \mathrm{~min}$.

Table 2 Attendance and treatment outcome for physiotherapy at Site B among matched referrals from Site A

Outcome for all referrals made to physiotherapy at Site B and matched with Site A records $(n=25)$

Did not attend first appointment

Attended initial appointment, but did not attend a subsequent appointment and were then discharged from the service

Completed treatment

Treatment ongoing

\section{$9(36 \%)$}

$7(28 \%)$

$5(20 \%)$

$4(16 \%)$ 
Table 3 Outcome of physiotherapy treatment sessions at Site B among those referred from Site A

Physiotherapy sessions registered for patients referred from Site A to Site B $(n=81)$

\begin{tabular}{lc}
\hline Attended & $49(60 \%)$ \\
Cancelled (either by service or by patient) & $14(17 \%)$ \\
Not attended & $18(22 \%)$ \\
Mean number of sessions for patients who completed & 4 \\
treatment &
\end{tabular}

During the interviews, staff explored and discussed the quantitative findings. They had various perspectives on the information presented to them, but there was often consistency across their responses. This process provided a breadth of insight and understanding to the quantitative findings. Themes identified included: recognition of homeless people's high incidence of musculoskeletal problems paired with an expectation that there should have been more physiotherapy referrals in the time frame; considerations given before referring to physiotherapy; reasons for missing physiotherapy appointments; perceptions of what physiotherapy offers and suggestions for making physiotherapy more accessible.

There was consensus that the characteristics of patients referred to physiotherapy reflected the wider homeless population attending their practice. Most interviewees noted that musculoskeletal problems were extremely common among their patients.

back problems are a huge bulk of what we see generally. Back, neck, shoulder, upper limb, knee, ankle...Lots of back problems

-Helen, Clinical Nurse Specialist

As a result, there was surprise at the low physiotherapy referral rate. However, numerous explanations for the this were offered, including: non-recording of referrals on the computer system; the relatively small practice size (approximately 900 registered patients) or a belief that patients' culture or language might limit their understanding of physiotherapy, thereby fostering an unwillingness to be referred.

... [patients] not understanding why we are sending them to physio, and that there is more to it than 'we just want you to do some exercises'

-Margaret, Nurse Practitioner In addition, in a population with multiple morbidities, musculoskeletal problems might not always be the most pressing health problem.

It's impossible to tackle everything in every patient that comes in... I wouldn't bombard someone with six referrals when I first see them, even though each of the six conditions they come in with, you would be referring in another population... The morbidity is so high... that we have to help prioritise and we have to make sure we don't scare people off...

-Yvonne, GP
Equally, patients may underplay their symptoms, choosing to manage them themselves.

I think most people who come in have some musculoskeletal problems, which they underplay and they self-medicate.

-Yvonne, GP

System-related factors may also be important, as appointment letters may have failed to reach patients who regularly changed their address.

OK we've referred them, do they actually get the appointment, if they haven't got an address? If they have to come to [our practice] to collect their post, how good are they at collecting their post?

-Helen, Clinical Nurse Specialist

There was also the belief that the referral process and waiting times were long, causing homeless patients to prioritise other issues when they were offered an appointment.

the general slowness in response to physio referrals... the more acute things we may be less likely to refer because we know it will be a month before we get a response, and appointment some time after that

-Alan, GP

Staff also considered patient-related factors before referring, such as symptom severity and chronicity, perceived benefits of physiotherapy and the challenges homeless people face attending appointments. Interviewees seemed reluctant to refer homeless patients, as they did not believe that such patients would attend the service.

Our referral rates are probably lower than for the amount of severe morbidity we see, I suspect, because we are anticipating high DNA [patient not attending] rates

-Yvonne, GP

Participants cited many reasons why homeless people might fail to attend appointments, including: not prioritising their health; poor timekeeping; language barriers; addiction, mental health problems and chaotic lifestyles.

But obviously with homelessness, if they get to sleep at someone's house and it is far away, it's difficult for them [to get to appointment].

-Kim, Receptionist

with drug and alcohol problems, [some] tend to be less good attenders... partly because they may still be under the influence even if they were intending to attend. 
-Alan, GP

Interviewees thought that an uptake of about a third $(36 \%)$ was reasonably successful for this patient group, considering the challenges they have in attending health services. Interviewees felt that non-attendance to follow-up appointments could be due to misunderstanding about what physiotherapy offers. One participant paraphrases a conversation she had with a patient.

'Oh I went there... the physio looked at me, and he just said I must stretch a few times, how is that supposed to fix my problem?'

-Margaret, Nurse Practitioner

Other suggestions were that perhaps one appointment sufficiently alleviated symptoms, or symptoms were improving by the time they reached physiotherapy. Alternatively, one participant suggested homeless people may have had an unpleasant experience at their initial appointment.

\section{I guess they are a population that are used to not getting the} greatest reception...

-Alan, GP

There was also a perception that physiotherapy may be evolving to place greater emphasis on self-management, with participants acknowledging that homeless people may not adhere to advice and exercise prescription.

much less physio is hands-on these days, and it's much more advice. So a lot of people... aren't that good at adhering to advice or doing exercise ... and they don't really believe that exercises are going to help.

-Yvonne, GP

Some noted that as housed people often struggle with exercise programme adherence, the additional challenge of precarious accommodation that homeless people face means that such exercise programmes are probably unrealistic.

I mean, where do they do their exercises if they are on the street, if they are squatting or sofa surfing?... that may be often a reason why people don't go back after their first appointment.

-Yvonne, GP

Consequently, participants said that they would often seek out alternatives in-house, rather than referring externally. For example, they might provide in-house injection therapy, analgesia, exercise, advice or information leaflets instead of onwards referral.

When I began to realise that actually quite a lot of what my patients were getting was advice and exercise sheets, well actually, some of that I can do

-Yvonne, GP

Conversely, one interviewee commented on how physiotherapy could offer an alternative to analgesia in a patient population that often has addiction problems.

In a group of people who substance misuse, we try and reduce our issuing of prescriptions as much as possible... analgesia is very high on the agenda...

-Margaret, Nurse Practitioner
Interviewees stated the need to manage the expectations of homeless people, as they may lack awareness about what physiotherapy involves.

you [the homeless person] actually have to attend... and then you [the practitioner] are not telling them go away with nothing, we can help, but you [the homeless person] have to help yourself in the process

-Margaret, Nurse Practitioner

Analysis suggested that approaches to potentially improve homeless peoples' attendance to physiotherapy mirrored explanations for why they may fail to attend. These included: better prompting, perhaps with texts to mobile phones; a self referral process; shorter waiting times and the ability to get an appointment at the time of making the referral. With these ideas in mind, there was a feeling that it was worth testing how referral to and uptake of a physiotherapy service might increase if it were on site in the GP practice, because they recognise that their homeless patients may prefer going somewhere familiar.

familiarity of the practice, they know where they are coming.

They perhaps have the trust of something offered under the general practice roof, where they are used to coming. -Alan, GP

\section{DISCUSSION}

The study succeeded in achieving its aims by collecting and descriptively reporting quantitative information about homeless people referred to physiotherapy by a dedicated GP practice. The quantitative findings were then thoroughly explored via the qualitative interviews with referring staff, offering detailed contextual insight. This study is important because physical health problems, including those of musculoskeletal origin, such as traumatic injury, ${ }^{20}$ are prevalent among homeless people, but there is limited understanding of how they currently are managed. Certainly, the quantitative findings of this study highlight a potential mismatch between the high incidence of musculoskeletal problems in the homeless population ${ }^{3}$ and the few homeless people accessing physiotherapy. The recognised lack of GP registration among many homeless individuals ${ }^{6}$ cannot explain poor access here, as the study was undertaken within a GP practice solely caring for homeless people. Although the referral rate of the GP practice in this study was found to be only slightly lower than a practice serving a predominantly housed population in the same locality, this study would suggest that barriers to attending physiotherapy are a significant issue to the homeless population, as their failure to attend initial appointments was greater than that of the general population referred to physiotherapy at Site B during the same time frame. Barriers to attending primary care appointments have been described as including frequent moving between areas, a chaotic lifestyle and lack of transport, ${ }^{6}$ findings that were supported by the qualitative phase of this study. 
Explanations for the decisions made by practice staff about whether to refer homeless patients to physiotherapy were wide ranging. Perceptions that patients lacked understanding about physiotherapy were one consideration, a view that supports the findings of the physiotherapists working with homeless people in Glasgow. ${ }^{10}$ This would suggest that there is value in promoting understanding among homeless people and key support staff. Staff also felt that system structures did not facilitate homeless people's attendance. Traditional processes of referrals, followed by appointment letters sent to patients' addresses, rigid appointment times and long waiting periods may not be ideal for this population. The GP practice in this study provided care solely to homeless people, whereas the receiving physiotherapy department served the whole community. It is suggested that primary healthcare programmes specifically tailored to meet the needs of homeless people might be more effective in the achievement of positive health outcomes than standard primary healthcare. ${ }^{21}$ Although the homeless people in this study had a dedicated GP practice sensitive to their care needs as their first point of contact, there were still barriers to their access imposed. Programmes that emphasise easy access, such as Crisis at Christmas ${ }^{15}$ and the drop-in and out-reach models in Glasgow, ${ }^{10}$ may facilitate increased access to these services.

Our findings might help explain why some GPs choose to manage patients themselves rather than referring them to physiotherapy. However, this course of action potentially denies those patients access to the broader range of skills a physiotherapist could offer, including a detailed knowledge of musculoskeletal conditions and rehabilitation techniques (exercise therapy, electrotherapy, acupuncture, manual therapy and self-management). However, the quantitative data regarding interventions provided to the patients within this study did show that physiotherapy treatment received was predominantly advice and exercise, which certainly resonated with the interviewees. It is possible that the patients who attended but did not complete their course of physiotherapy only needed advice and exercise, and therefore elected not to return. Alternatively, the physiotherapists may not have had adequate training or were ill-equipped to handle the underlying addiction issues and challenging behaviours that homeless individuals may present with.

The conclusions drawn here are limited by this being a small, exploratory study. Consequently, the findings may have limited application in other settings. Ethical approval stipulated that all patient data reaching the research team must be anonymous, so it was impossible to use patient NHS numbers or dates of birth during quantitative data collection. Consequently, using four patient characteristics to match data across the two sites was problematic, resulting in a failure to match nine patient records. Although it is not known exactly why matching for all patient records was not possible, some suggestions include variability of dates used to signify referral transfer between sites and certainly on some records' data was incomplete. During the qualitative phase, staff looking after homeless people were interviewed, but homeless people were not. By leaving the perspective of the homeless people out of this work, a degree of bias was potentially added.

Clearly, more work is needed if homeless people are to receive more comprehensive care. Future research in this field should include input from homeless people themselves, and investigation into education and shared practice between physiotherapists and GPs. The complex mix of physical, mental and social problems faced by homeless people means that both attendance at and compliance with care services are a challenge. Co-operation between agencies to reduce these barriers would be beneficial; for example, piloting physiotherapy services within GP practices that care for homeless people could facilitate better attendance. Nevertheless, even if such care resources are available, findings suggest that homeless people's ability to access them is currently limited by numerous factors. Equally, there may be ways forward for improving care by relatively simple service redesign.

Acknowledgements The authors would like to acknowledge the Faculty of Health Social Care and Education, Kingston University and St George's, University of London Small Grants Committee for funding this work. They would also like to acknowledge Dennis Carlton and Lisa Bellas for assistance with data searching and provision. Additionally, thanks are due to Dr Tim Elwell-Sutton and Rafael Sumalinog, the reviewers of this paper, whose guidance and feedback have been invaluable.

Contributors JD, SD and NG made substantial contributions to the conception or design of the work and were all involved in interpretation of data. JD was the principle investigator, primary collector of data and drafted the paper. JD and SD were both involved in data analysis. All authors revised the drafted work critically for important intellectual content, approved the final version to be published, agreed to be accountable to all aspects of the work, and ensure that questions related to the accuracy or integrity of any part of the work are appropriately investigated and resolved.

Competing interests None declared.

Patient consent No patients were directly involved in this research.

Ethics approval Faculty Research Ethics Committee, Faculty of Health, Social Care and Education, Kingston University and St Georges, University of London.

Provenance and peer review Not commissioned; externally peer reviewed.

Data sharing statement In line with the ethical approval granted for this study, no additional unpublished data will be shared from this study.

Open Access This is an Open Access article distributed in accordance with the Creative Commons Attribution Non Commercial (CC BY-NC 4.0) license, which permits others to distribute, remix, adapt, build upon this work non-commercially, and license their derivative works on different terms, provided the original work is properly cited and the use is non-commercial. See: http://creativecommons.org/ licenses/by-nc/4.0/

(c) Article author(s) (or their employer(s) unless otherwise stated in the text of the article) 2017. All rights reserved. No commercial use is permitted unless otherwise expressly granted.

\section{REFERENCES}

1. Hewett N, Halligan A, Boyce T. A general practitioner and nurse led approach to improving hospital care for homeless people. BMJ 2012;345:e5999.

2. Geddes JR, Fazel S. Extreme health inequalities: mortality in homeless people. Lancet 2011;377:2156-7. 
3. Link H. Health needs Audit- Explore the data. http://www.homeless. org.uk/facts/homelessness-in-numbers/health-needs-audit-exploredata (accessed 16 Mar 2016).

4. Health and Social Care Information Centre Health Survey England - 2013. Health Social Care and Lifestyles. 2014 http://nesstar. ukdataservice.ac.uk/webview/ (accessed: 22 Mar 2016).

5. Trevena LJ, Nutbeam D, Simpson JM. Asking the right questions of disadvantaged and homeless communities: the role of housing, patterns of illness and reporting behaviours in the measurement of health status. Aust N Z J Public Health 2001;25:298-304.

6. Elwell-Sutton T, Fok J, Albanese F, et al. Factors associated with access to care and healthcare utilization in the homeless population of England. J Public Health 2017;39:1.

7. Flanagan SM, Hancock B. 'Reaching the hard to reach'--lessons learned from the VCS (voluntary and community Sector). A qualitative study. BMC Health Serv Res 2010;10:92.

8. Department of Health. Self referral pilots to musculoskeletal physiotherapy and the implications for improving access to other AHP services. http://webarchive.nationalarchives.gov.uk/ 20130107105354/http://www.dh.gov.uk/en/Publicationsandstatistics/ Publications/PublicationsPolicyAndGuidance/DH_089516 (accessed: 20 Jan 2016).

9. Department of Health. Healthcare for single homeless people. http:// webarchive.nationalarchives.gov.uk/20130107105354/http://www. dh.gov.uk/prod_consum_dh/groups/dh_digitalassets/@dh/@en/@ps/ documents/digitalasset/dh_114369.pdf (accessed: 20 Jan 2016).

10. Dawes J, Brydson G, McLean F, et al. Physiotherapy for homeless people: unique service for a vulnerable population. Physiotherapy 2003;89:297-304.

11. Crisis. About homelessness: briefing on key homelessness facts and statistics. http://www.crisis.org.uk/pages/homeless-def-numbers. html (accessed 1 Feb 2016).
12. Link H, homeless $\mathrm{S}$. Regional breakdown. http://www.homeless. org.uk/facts/homelessness-in-numbers/statutory-homelessness (accessed 1 Feb 2016).

13. Chartered Society of Physiotherapy. Self-referral in the United Kingdom http://www.csp.org.uk/professional-union/practice/selfreferral/self-referral-united-kingdom (accessed $1 \mathrm{Feb} 2016$ ).

14. Crisis. Crisis at Christmas Physiotherapy Service Use 23/12/2014 to 30/12/2015. C-log database. Crisis by request (accessed 20 January 2016).

15. Morgan D. Follow-up Qualitative Extensions to Core Quantitative Research Projects. Qualitative I, Qualitative methods A pragmatic approach. London: sage, 2014:153-78.

16. Lincoln Y. Guba E, and Guba E naturalistic inquiry: the paradigm revolution. London: SAGE, 1985.

17. Braun V, Clarke V. Using thematic analysis in psychology. Qual Res Psychol 2006;3:77-101.

18. Geertz C. Thick descriptions: Towards an interpretive theory of culture. The interpretation of cultures: selected essays. New York: Basic Books, 1973:3-30.

19. Homerton University Hospital NHS Foundation Trust. Integrated Medical and Rehabilitation Services Division Physiotherapy Service Attendance Data 01/10/13 and 30/06/14. Available from: Homerton University Hospital NHS Foundation Trust, Integrated Medical and Rehabilitation Services Division by request. (accessed 17 Feb 2016).

20. Wright NM, Tompkins CN. How can health services effectively meet the health needs of homeless people? $\mathrm{Br} J$ Gen Pract 2006;56:286-93.

21. Hwang SW, Burns T. Health interventions for people who are homeless. Lancet 2014;384:1541-7. 